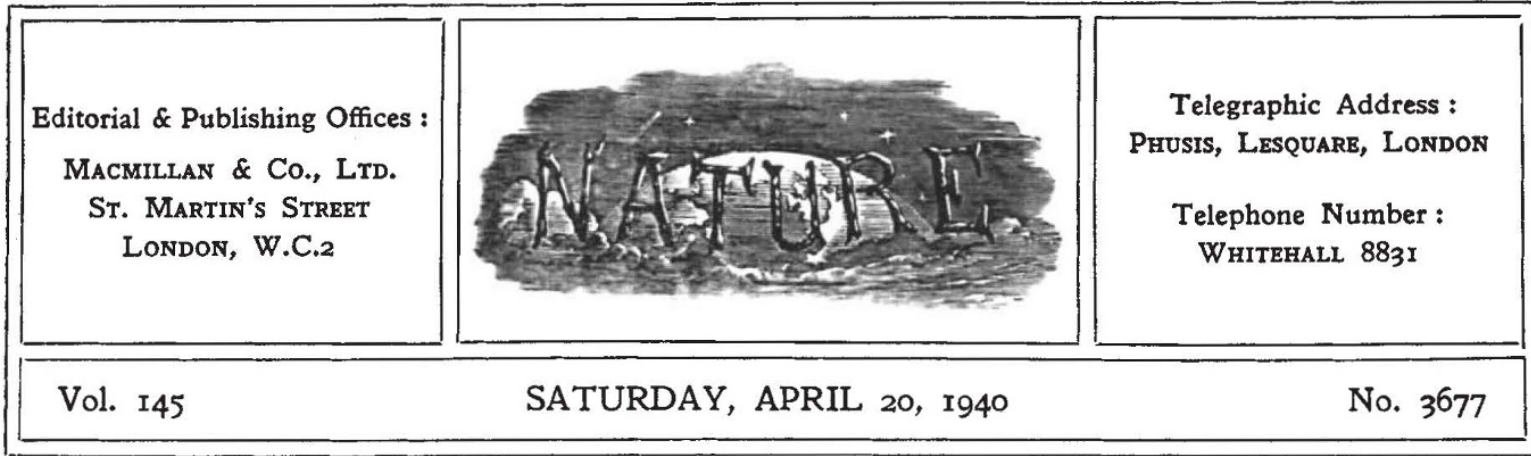

\title{
LOCATION OF INDUSTRY IN GREAT BRITAIN
}

$\mathrm{T}$ HE Royal Commission on the Distribution of the Industrial Population, under the chairmanship of Sir Montague Barlow, was appointed in July 1937, mainly in consequence of the concern at the slow recovery of the Depressed Areas and the steady drift of population to London and the Home Counties. The views so strongly expressed by successive Commissioners for the Special Areas, without apparent effect, had by then been powerfully reinforced by defence considerations. The strategical dangers to which the whole country was exposed by over-development in its most vulnerable part could no longer be ignored, and the possibility of experimenting in national planning had at last to be considered seriously by the Government.

When the Royal Commission was appointed, an inquiry into the location of industry undertaken by a group of Political and Economic Planning had already reached an advanced stage. The latter inquiry, in view of its relation to the work of other P E P groups, was nevertheless carried to a conclusion and its report was published in March of last year. It is not surprising, therefore, that the recently published report of the Royal Commission, a summary of which appears elsewhere in this issue, provides little additional information, but nevertheless it gives us an able and well-balanced survey of the situation.

Both in the basic facts which are set forth and in the conclusions and recommendations deduced from them, the two reports have much in common. Where the Planning Group of P E P recommends the creation of a permanent Industrial Development Commission for the specific purpose of guiding the location of industry and advising the Government on the subject, the majority report of the Royal Commission recommends the appoint- ment of a National Industrial Board, with mainly advisory powers except in regard to regulation of industrial location in London and the Home Counties. There is, however, a wide divergence of opinion among the members of the Royal Commission in regard to the functions to be exercised by the central authority. Three of the ten members who sign the majority report do so with reservations which would bring the functions of the proposed Board closely into line with those of the Development Commission recommended in the $\mathrm{P} \mathrm{E} \mathrm{P}$ report. The remaining three members of the Commission go even beyond the P E P report, which suggested that a senior Cabinet Minister without departmental duties should be responsible to Parliament for the activities of the Commission, and recommend the establishment of a new ministry, taking over not only the functions of the Commissioners for the Special Areas, but also some of the functions of the Ministry of Health and Ministry of Transport.

This sense of urgency and note of conviction, which characterize both the reservations and the minority report, give a value and reality to the outcome of the Commission's labours which would otherwise be sadly lacking. Without them it could scarcely be said that the report does more than give us a fresh and convenient presentation of facts already widely known, leading to conclusions previously reached by many thoughtful observers and students of problems of industrial location or planning. The bare majority of the Commission appears to falter just where decision and action are most needed, and the ably argued reservations of Prof. J. H. Jones, Mr. G. W. Thomson and Sir William Whyte in the minority report are likely to carry much more conviction with scientific workers. 
The signatories of the minority report regard the excessive concentration of population in London and other large conurbations as more a symptom of the main disease than as an evil in itself, although socially and strategically they agree with the other commissioners that it is an evil which requires remedying at the earliest possible moment. They urge, therefore, that positive action by way of regulating new industrial development throughout Great Britain is a more essential and effective way of treating the problem than simple restriction of the industrial growth of a particular area. A beginning must be made in treating the country as a social and economic unit as well as a political unit.

The logic of such a policy can scarcely be denied if there be agreement on the basic facts from which it is derived. Moreover, only continuous study by the new Board of the problem of achieving a well-balanced industrial society can obviate the creation or perpetuation of areas of great distress in the near future. The facts assembled in the report should finally dispose of any lingering contention that we can rely on unguided or uncontrolled private industry in such matters without detriment to the social, economic, and strategic interests or amenities of the nation. The unassailable fact demonstrated by this report, like that of the P E P report, is that apart altogether from the difficulties and complications of co-ordination and clashing of interests, neither the industrialist nor the individual Government department has usually anything like the s mount of information required for a sound decision as to location. Decisions based on a partial knowledge of the facts have been invalidated by unforeseen developments elsewhere with consequences no less disastrous to the enterprise itself than to the district and community in which it was mistakenly placed.

For such reasons as these there is general agreement that a beginning should be made with London ; but the experience gained with restrictive powers in that region should be used from the start as a guide in preparing a scheme to be applied to the whole of Great Britain. No district should be considered or dealt with other than as one part of a national problem, and the whole experience of the past few months of war endorses the urgency of the minority argument or reservation on this point in the report. Accordingly, once the necessity of conferring immediate executive powers on the proposed Board in respect of London and the Home Counties is admitted, it appears to be illogical to withhold the general executive powers which are advocated by six out of the thirteen members of the Royal Commission.

The difference between the bare majority and the remaining members of the Royal Commission appears to be much more profound than is indicated by mere reservations. Having regard to the urgency of the problem, accentuated by all the disturbance of civil life which the War has since occasioned, the choice between advisory powers and executive powers may make all the difference between success or failure in the formulation and execution of an adequate plan.

This point of view is endorsed by the experience of the Commissioners for the Special Areas. Evidence submitted to the Royal Commission showed not only that the Commissioners had made the fullest use of their powers and opportunities, but also that their powers had been too rigidly defined and were too restricted in scope. The solution to the problem of the Special Areas does not necessarily lie within the defined geographical limits of such areas, any more than the problem of location of industry can be separated from the national problem of persistent unemployment. Moreover, the Commissioners for the Special Areas are not empowered to do more than endeavour to remedy-or mitigate-a serious evil that has already appeared. Anticipation and prevention lie outside their province.

These considerations led the minority of the Commissioners to recommend that the essential powers and responsibilities of the Commissioners for the. Special Areas should be transferred either to the new Board recommended in the majority report, or to the new Ministry recommended in the minority report, and that they should be extended to cover the whole of Great Britain. The basic purpose of such extension is to provide preventive rather than curative action, so far as possible, and the intensity of armament production at the present time emphasizes the warning that, in the absence of such preparation for the future, the problems of the past will reappear, and become even more serious in extent and more difficult to solve.

This is indeed one of the dominant notes throughout the reservations and the minority report, and a basic consideration in putting forward recommendations for wider executive powers and immediate action. A policy of drift is likely now, even more than when the report was written, to lead to the perpetuation and exaggeration of existing evils. The continuance of ineffective 
control may also result in irremediable damage to the countryside and amenities through unrestricted despoliation and haphazard development arising out of evacuation, decentralization and the building of camps, whether civil or military.

The salient feature in the existing situation is that little, or in any event insufficient, attention has been given to the problem of the best distribution of industry in Great Britain as a whole. Not only are the town planning schemes local by definition, but also much of the basic knowledge required to guide industry in the choice of sites is lacking. The necessity for unified research into the problem of distribution on a national scale is widely recognized. On this, and on the necessity for a unified plan of distribution based on the results of such research, and for effective control meanwhile of such changes in distribution as must continue to take place in the interests of trade, the Royal Commission is virtually unanimous. The minority only differs from the majority in considering that this task, which is both national and local, is of sufficient importance to call for the creation of a new separate Ministry, on the same principle as that on which separate Ministries have been created in the past for the partly national and partly local services of education and transport.

The divergence of views on the Commission in regard to the urgency and machinery of Government action should not be allowed to overshadow the basic fact that the Commission is unanimous in its nine main conclusions as to the objectives of that action. Moreover, the evidence demonstrated the existence of a large body of opinion in favour of some regulating action along national lines and in the national interest. It is indeed possible to regard the essential difference between the majority and minority recommendations as consisting in the greater regard had by the former to action which is immediately practicable, rather than to that which is theoretically desirable but would demand further educational effort to secure adequate support.

If, therefore, the wider vision and longer range objectives which characterize the minority recommendations are kept in mind, adoption of the majority report and action along the lines advocated by it is more likely than not to prove a stepping stone to the wider and more extensive powers contemplated by the remaining Commissioners. The task of education can proceed pari passu with such action, and the impetus to regionalism which the report can scarcely fail to give-which has indeed already been given by civil defence and other emergency measures in war-time-should further assist in that process.

What has to be kept in mind is the importance of immediate action. The report must not be merely shelved until after the War. The nation cannot afford to leave great industrial areas of the country derelict and allow development to repeat the process elsewhere. There is no guarantee that the new and expanding industries of to-day will not be the depressed industries of to-morrow if allowed to develop without control. Moreover, developments proceeding in war-time require co-ordination and control if the problem is not to become even more intractable, with further waste of national assets, spoliation of amenities, injury to national health and destruction of the countryside.

The report has therefore the strongest claims on the attention of all who are concerned with the scientific utilization and conservation of national resources in the widest sense. The co-operation of scientific men is essential in much of the basic research work required and in the elaboration of the necessary plans for development. On a score of technical questions it will fall within their competence to give the appropriate data. Above all, the problem must be considered in relation to that task of reconstruction which will confront us urgently at the end of the War, and possibly the more imperatively the longer the War lasts. We cannot afford to wait until irreparable damage is done, and solutions have to be found urgently and decisions made under duress and with no sound basis. The extensive and realistic research and planning upon which peaceful change depends, whether in national or international affairs, cannot be improvized in a moment. The location of industry is typical of those problems which must be visualized and handled before they become chronic or acute, and before their reactions on other problems multiply. Already, as the report shows plainly, the maldistribution of the industrial population of Great Britain has reached a point when it may easily become intractable.

The problem is a vital part of our war effort, and if that is to attain its maximum efficiency and the subsequent task of reconstruction is not to be hindered, it must be faced at once. The report of the Barlow Commission points out certain possible lines of immediate advance, and provides fresh material with which to win the support of the community for progressive measures in dealing with the distribution of the industrial population of Great Britain. 